\title{
Relationship between expression of PD-L1 and PD-L2 on esophageal squamous cell carcinoma and the antitumor effects of $\mathrm{CD8}^{+} \mathrm{T}$ cells
}

\author{
CHANGSEN LENG ${ }^{1}$, YIN LI $^{1}$, JIANJUN QIN ${ }^{1}$, JUN MA $^{2}$, XIANBEN LIU ${ }^{1}$, YINGYING CUI ${ }^{3}$, \\ HAIBO SUN ${ }^{1}$, ZONGFEI WANG ${ }^{1}$, XIONGHUAI HUA ${ }^{1}$, YONGKUI YU ${ }^{1}$, HAOMIAO LI $^{1}$, \\ JUN ZHANG ${ }^{1}$, YAN ZHENG ${ }^{1}$, WEI WANG ${ }^{1}$, JUNWEI ZHU ${ }^{1}$ and QIUMING WANG $^{2}$ \\ ${ }^{1}$ Department of Thoracic Surgery, The Affiliated Cancer Hospital of Zhengzhou University, Zhengzhou, \\ Henan 450008; ${ }^{2}$ The Second Affiliated Hospital of Zhengzhou University, Zhengzhou, Henan 450014; \\ ${ }^{3}$ The First Affiliated Hospital of Zhengzhou University, Zhengzhou, Henan 450052, P.R. China
}

Received July 4, 2015; Accepted August 18, 2015

DOI: $10.3892 /$ or.2015.4435

\begin{abstract}
The programmed death-1 (PD-1)/programmed death-ligands (PD-Ls) signal pathway has been implicated as a potential immune escape mechanism in several human cancers. However, the studies of PD-1/PD-Ls pathway in esophageal squamous cell carcinoma (ECSS) are not yet sufficient. The current study investigated the expression of PD-L1, PD-L2 and PD-1 in ESCC tissues. The correlations between the expression of these proteins and clinical histopathological parameters were analyzed. Then the stable transfected Ec109 cell lines overexpressing PD-L1/PD-L2 were established by plasmid transfection successfully. Ec109 and $\mathrm{CD} 8^{+} \mathrm{T}$ cells were co-cultured to analyze the effects of PD-1/PD-Ls signal pathway on the function of $\mathrm{CD}^{+} \mathrm{T}$ cells including proliferation, apoptosis and interferon- $\gamma$ production. We found that PD-L1-positive patients had significantly poorer prognosis than the negative patients, while their prognosis was not related to PD-L2 expression. The count of PD-1+ $1^{+}$TILs (tumor-infiltrating lymphocytes) was negatively correlated with both PD-L1 and PD-L2 expression. In functional studies, we found that PD-1/PD-Ls signal pathway was able to downregulate the function of $\mathrm{CD}^{+} \mathrm{T}$ lymphocyte and its function could be restored by blocking the signal pathway. This indicates that PD-1/PD-Ls may prevent effective antitumor immunity, which provides important evidence to delineate the cellular immune deficiency mechanism in ESCC. Therefore, PD-1/PD-Ls are predicted to become novel targets for ESCC immunotherapy.
\end{abstract}

Correspondence to: Professor Yin Li, Department of Thoracic Surgery, The Affiliated Cancer Hospital of Zhengzhou University, 127 Dongming Road, Zhengzhou, Henan 450008, P.R. China E-mail: liyin0825@126.com

Key words: esophageal squamous cell carcinoma, programmed death-1, programmed death-ligands, immunotherapy

\section{Introduction}

Esophageal cancer is the sixth leading cause of cancer-related death worldwide and one of the most difficult malignant tumors to treat and cure (1). Squamous cell carcinoma is responsible for $95 \%$ of all esophageal cancers worldwide $(2,3)$. Although advances have been made in the therapy with multimodal treatment strategies, including neoadjuvant chemotherapy or radiochemotherapy, esophageal cancer still remains one of the most deadly human malignancies. In addition, neoadjuvant chemotherapy and radiochemotherapy also bring many complications (4-6). Therefore, it is urgently necessary to study the pathogenesis of esophageal cancer and explore new treatment approaches.

The ability to evade immune surveillance is a well accepted feature of malignant tumors. Recently, manipulation of costimulatory signaling has been implicated as a potential immune escape mechanism in human cancer (7-9). Costimulatory signaling plays a key role in the initiation and termination of immune responses by regulation of T-cell activation (10).

Programmed death-1 (PD-1) is a costimulatory molecule that provides an inhibitory signal in T-cell activation. PD-1 belongs to the CD28 family $(11,12)$. PD-1 is expressed on T cells, $\mathrm{B}$ cells and myeloid cells. Programmed death-ligands (PD-Ls) are ligands for PD-1, including PD-L1 and PD-L2, which are cell-surface glycoprotein belonging to the B7 family (13-16). Previous studies have shown that PD-1/PD-Ls interaction inhibits the function of $\mathrm{T}$ cell $(14,16)$.

Recently, aberrant PD-L1 and PD-L2 expression by cancer cells has been reported in many human malignancies (17-19). A series of clinical trials concerning the systemic administration of therapeutic antibodies for blocking PD-1 or PD-L1 have shown a promising clinical effect in various tumors $(20,21)$. However, further studies on the PD-1/PD-Ls pathway in esophageal squamous cell carcinoma (ESCC) are required. There is no previous study on the expression of PD-L1, PD-L2 and PD-1 simultaneously in ESCC tissues. The association between their expression and ESCC 
prognosis is still controversial, and the mechanism of the PD-1/PD-Ls pathway in ESCC is not clear. Our research is likely to provide important evidence to delineate the cellular immune deficiency mechanism in ESCC and a potential strategy for immunotherapy against ESCC.

\section{Materials and methods}

Tissue samples. We examined 106 patients with esophageal cancer who underwent surgery at Department of Surgery, the Affiliated Cancer Hospital of Zhengzhou University, between January 2008 and December 2009. The patients had undergone primary surgical resection with curative intent without preoperative chemotherapy or radiotherapy. Seventy-six patients were male and 30 were female. The median age of the patients was 59 years, with a range of 38 to 80 years. Tumor stage was defined according to the pathological tumor node metastasis (pTNM system) classification proposed by the International Union against Cancer (UICC/AJCC, 7th edition) [stage I $(n=17)$, stage II $(n=61)$, stage III $(n=23)$ and stage IV $(n=5)]$. The median follow-up time for all patients was 55 months. Postoperative pathohistologic analysis indicated that all tumors in this study were ESCC. We also obtained 30 cases of paracancerous tissue ( $>5 \mathrm{~cm}$ away from the cancer margin) as control.

Immunohistochemistry (IHC). The IHC streptavidin-peroxidase staining method was performed on $5 \mu \mathrm{m}$-thick formalin-fixed and paraffin-embedded tissue sections. The sections were deparaffinized in xylene, rehydrated in gradient ethanol solutions. The antigen retrieval was conducted in $0.01 \mathrm{~mol} / 1$ citrate $(\mathrm{pH} \mathrm{6.0)}$. Slides were incubated overnight with rabbit anti-human PD-L1 polyclonal antibody (1:40; ab58810; Abcam, Cambridge, MA, USA), rabbit anti-human PD-L2 polyclonal antibody (1:60; AB21968a; Sangon, Shanghai, China), mouse anti-human PD-1 monoclonal antibody (1:50; ab52587; Abcam) and phosphate-buffered saline as blank control. Incubation of the biotinylated secondary antibody with horseradish peroxidase and 3, 3'-diaminobenzidine chromogen (all from ZSGB-Bio, Beijing, China) was performed sequentially. Next, the slides were counterstained with hematoxylin and then covered with neutral balsam.

Evaluation of IHC. IHC results for all examined costimulatory molecules were evaluated by scanning each slide under low-power magnification (x40) to identify regions containing positive immunoreactivity. Immunostaining was further evaluated at high-power magnification (x200). Tumor samples were examined by two observers in a blinded manner. Expression of PD-L1, PD-L2 and PD-1 was evaluated as staining on the cell membrane and cytoplasm. PD-L1 and PD-L2 stainingpositive cases were determined by staining intensity and the positive cell percentage according to the methods previously published $(22,23)$. The staining intensity grading: 0 point (no staining), 1 point (faint yellow), 2 points (claybank), 3 points (sepia). The percentage of the tumor cell population staining was scored as follows: 1 point $(<10 \%)$, 2 points $(10-50 \%), 3$ points $(>50 \%)$. The positive cases were determined according to the two items multiplied by products: positive ( $>3$ points), negative ( $\leq 3$ points). The mean count of PD- $1^{+}$TILs (tumor-infiltrating lymphocytes) of 106 cases was used as threshold and the cases were divided into high PD- $1^{+}$TILs group and low PD- $1^{+}$TIL group according to the threshold.

Cells and cultures. The Ec109 cells were cultured in RPMI-1640 (Biological Industries, Kibbutz Beit. Haemek, Israel) supplemented with $10 \%$ fetal bovine serum (FBS), (Biological Industries), $2 \mathrm{mmol} / 1$ glutamine, $100 \mathrm{U} / \mathrm{ml}$ penicillin, and $100 \mu \mathrm{g} / \mathrm{ml}$ streptomycin at $37^{\circ} \mathrm{C}$ in $5 \% \mathrm{CO}_{2}$. The lymphocytes were provided by the Biological Treatment Center of the Second Affiliated Hospital, Zhengzhou University. Cells were plated into culture flasks with the medium at the concentration of $2 \times 10^{6} / \mathrm{ml}$ and placed at $37^{\circ} \mathrm{C}$ in $5 \% \mathrm{CO}_{2}$. The lymphocytes were sampled and counted every 2-3 days maintained at $1-4 \times 10^{6} / \mathrm{ml}$ by supplementing culture medium or subculture. The cells were harvested between day 10 and day 17. Lymphocyte culture medium was similar with cancer cell medium above, except added with 1,000 U/ ml interleukin (IL)-2 (KEXIN, Beijing, China).

Magnetic activated cell sorting (MACS). The $\mathrm{CD}^{+} \mathrm{T}$ cells were generated using miniMACS system. The lymphocytes were labeled with anti-CD8 microbeads (Miltenyi Biotec $\mathrm{GmbH}$, Bergisch Gladbach, Germany). The isolation was carried out according to the manufacturer's instructions. The purity of $\mathrm{CD}^{+} \mathrm{T}$ cells was measured by flow cytometry (FCM). Then $\mathrm{CD}^{+} \mathrm{T}$ cells were cultured in lymphocyte culture medium.

Transfection. The PD-L1 and PD-L2 cDNA were digested with $K p n \mathrm{I} / \mathrm{XhoI}$ and constructed into pcDNA3.1 expression vector by Sangon Biotech (Shanghai, China). Ec109 cells were cultured in a 6 -well plate $\left(1 \times 10^{6} /\right.$ well). When the cells were $70 \%$ confluent, they were used for transfection with pcDNA3.1/PD-L1, pcDNA3.1/PD-L2 or pcDNA3.1, respectively. The complex of DNA-Lipofectamine 2000 (Invitrogen, Carlsbad, CA, USA) was prepared according to the manufacturer's instructions and was added to the culture wells. The culture plate was shaken gently so that the complex of DNA-Lipofectamine 2000 distributed well. Ec109 cells were cultured for another $4 \mathrm{~h}$, and then culture medium was replaced by fresh medium. The transfected Ec109 cells (Ec109/PD-L1, Ec109/PD-L2 and Ec109/mock) were cultured for $48 \mathrm{~h}$. Then $\mathrm{G} 418(400 \mu \mathrm{g} / \mathrm{ml})$ was used to select the stable transfection clones.

FCM. FCM was performed by standard method. The data were acquired by using a FACSCanto cytometer (Becton-Dickinson, Franklin Lakes, NJ, USA) and analyzed by CellQuest Pro software. Monoclonal antibody used to measure the purity of $\mathrm{CD}^{+} \mathrm{T}$ cells before and afer MACS included mouse anti-human-CD8-PE, -CD3-PerCP (both from Miltenyi Biotec). The following monoclonal antibodies were used to measure PD-1 expression of $\mathrm{CD}^{+} \mathrm{T}$ cells and PD-L1, PD-L2 expression of Ec109 cells before and after transfection: mouse anti-human -PD-L1-APC (Biolegend, San Diego, CA, USA), -PD-L2-Fitc and -PD-1-PE (both from Miltenyi Biotec). IgG isotype controls were used in FCM. 


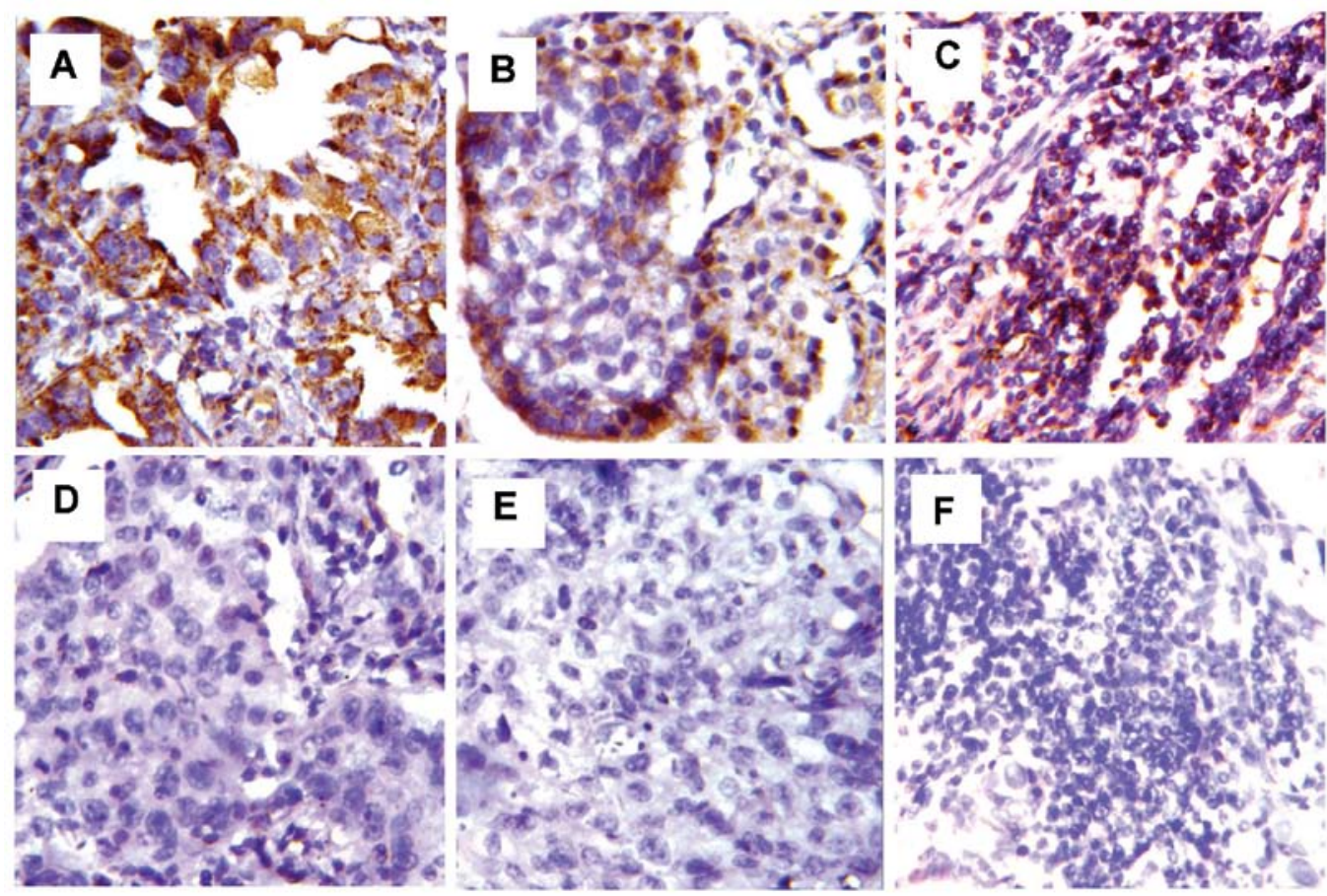

Figure 1. Immunohistochemical staining for human ESCC tissues. (A) PD-L1 positive, (B) PD-L2 positive, (C) PD-1 positive, (D) PD-L1 negative, (E) PD-L2 negative and (F) PD-1 negative. Original magnification, x200.

Real-time quantitative PCR (qRT-PCR). Ec109 cells before and after transfection in logarithmic growth phase were collected. The total RNA was extracted using the RNA extraction kit spin column method (Qiagen, Dusseldorf, Germany) according to the manufacturer's instructions. Finally, $50 \mu 1$ RNA was collected and RNA purity (D260/D280) was 1.8-2.0, tested using an ultraviolet spectrophotometer (SMA4000; Merinton, Beijing, China). Subsequently, reverse transcription was conducted according to the reverse transcription kit recommendations (Thermo Fisher Scientific, Inc., Waltham, MA, USA). In total, $20 \mu \mathrm{l}$ cDNA was obtained and stored at $-20^{\circ} \mathrm{C}$ until use. The following primers synthesized by Sangon Biotech Co., Ltd., Shanghai, China were used for cDNA amplification system: PD-L1: forward, 5'-GCATGGAGAGG AAGACCTGA-3' and reverse, 5'-TTGTAGTCGGCACCA CCATA-3'; PD-L2: forward, 5'-CAGCAATGTGACCCTGG AAT-3' and reverse 5'-GGACTTGAGGTATGTGGAACG-3'; $\beta$-actin as control. qRT-PCR was performed using the SYBR Green PCR kit (Qiagen) according to the manufacturer's instructions. Samples were denatured for $15 \mathrm{~min}$ at $95^{\circ} \mathrm{C}$, followed by 40 cycles including denaturation at $95^{\circ} \mathrm{C}$ for $15 \mathrm{sec}$, annealing at $52^{\circ} \mathrm{C}$ for $30 \mathrm{sec}$ and extension at $72^{\circ} \mathrm{C}$ for $34 \mathrm{sec}$, then by continuous fluorescence measurement during heating from $60^{\circ} \mathrm{C}$ to $90^{\circ} \mathrm{C}\left(0.1^{\circ} \mathrm{C} / \mathrm{s}\right)$. The data was normalized to the $\beta$-actin expression of Ec109 cells and analyzed using the ABI 7500 Fast system (Applied Biosystems, Foster City, CA, USA). $\Delta \mathrm{CT}=\mathrm{CT}$ (target gene) $-\mathrm{CT}(\beta$-actin $)$.

Co-culture. To delineate the role of PD-Ls in tumor-T-cell interactions in ESCC, co-culture experiments were carried out by simulating the tumor microenvironment. The following monoclonal antibodies were used to block PD-L1, PD-L2 and PD-1: mouse anti-human-PD-L1, mouse anti-human-PD-L2
(Biolegend), rabbit anti-human-PD-1 (Miltenyi Biotec). The experiments were divided into 6 groups for research on the PD-L1 signal: group (A) $\mathrm{CD}^{+} \mathrm{T}$ cells + Ec109/PD-L1 cells + IgG antibody; group (B) $\mathrm{CD}^{+} \mathrm{T}$ cells + Ec109/PD-L1 cells + PD-L1 antibody; group (C) CD8 ${ }^{+}$T cells + Ec109/PD-L1 cells + PD-1 antibody; group (D) $\mathrm{CD}^{+} \mathrm{T}$ cells + Ec109/mock cells + IgG antibody; group (E) $\mathrm{CD}^{+} \mathrm{T}$ cells + Ec109/mock cells + PD-L1 antibody; group (F) CD8 ${ }^{+}$T cells + Ec109/mock cells + PD-1 antibody. Another 6 groups for research on the PD-L2 signal: group (A) $\mathrm{CD}^{+} \mathrm{T}$ cells + Ec109/PD-L2 cells + IgG antibody; group (B) $\mathrm{CD}^{+} \mathrm{T}$ cells + Ec109/PD-L2 cells + PD-L2 antibody; group (C) CD8 ${ }^{+}$T cells + Ec109/PD-L2 cells + PD-1 antibody; group (D) $\mathrm{CD}^{+} \mathrm{T}$ cells + Ec109/mock cells + IgG antibody; group (E) $\mathrm{CD}^{+} \mathrm{T}$ cells + Ec109/mock cells + PD-L2 antibody; group (F) CD8 ${ }^{+}$T cells + Ec109/mock cells + PD-1 antibody. Each group was repeated at least five times.

CCK-8 cell proliferation assay. According to the above groups, $\mathrm{CD}^{+} \mathrm{T}$ cells $\left(5 \times 10^{4} /\right.$ well) were co-cultured in 96-well plates with mitomycin $(15 \mu \mathrm{g} / \mathrm{ml})$ treated Ec109 cells $\left(1 \times 10^{4} /\right.$ well $)$ at a ratio of 5:1. Cell co-cultures were maintained in complete media with recombinant human IL-2 $(1,000 \mathrm{U} / \mathrm{ml})$ and the antibodies $(10 \mu \mathrm{g} / \mathrm{ml})$. The proliferation of $\mathrm{CD}^{+} \mathrm{T}$ cells was estimated by CCK- 8 (Beyotime, Jiangsu, China). After co-cultured for $48 \mathrm{~h}, 20 \mu \mathrm{l}$ CCK-8 was added to each well. The absorbance of each well was measured with a microplate reader at $450 \mathrm{~nm}$.

Apoptosis. According to the above groups, $\mathrm{CD}^{+} \mathrm{T}$ cells $\left(5 \times 10^{4} /\right.$ well $)$ were co-cultured in 96 -well plates with Ec109 cells $\left(1 \times 10^{4} /\right.$ well) at a ratio of 5:1. Cell co-cultures were maintained in complete media with recombinant human 
Table I. The correlation between PD-L1, PD-L2 expression and clinicopathological characteristics of ESCC patients.

\begin{tabular}{|c|c|c|c|c|c|c|c|}
\hline \multirow[b]{2}{*}{ Characteristics } & \multirow[b]{2}{*}{ Total (n) } & \multicolumn{2}{|c|}{ PD-L1 } & \multirow[b]{2}{*}{ P-value } & \multicolumn{2}{|c|}{ PD-L2 } & \multirow[b]{2}{*}{ P-value } \\
\hline & & Positive & Negative & & Positive & Negative & \\
\hline \multicolumn{8}{|l|}{ Gender } \\
\hline Male & 76 & 42 & 34 & 0.624 & 44 & 32 & 0.908 \\
\hline Female & 30 & 15 & 15 & & 17 & 13 & \\
\hline \multicolumn{8}{|l|}{ Age (years) } \\
\hline$\geq 60$ & 58 & 33 & 25 & 0.478 & 35 & 23 & 0.834 \\
\hline$<60$ & 48 & 24 & 24 & & 28 & 20 & \\
\hline \multicolumn{8}{|l|}{ Tumor location } \\
\hline Proximal third & 6 & 4 & 2 & 0.460 & 4 & 2 & 0.414 \\
\hline Middle third & 83 & 42 & 41 & & 45 & 38 & \\
\hline Distal third & 17 & 11 & 6 & & 12 & 5 & \\
\hline \multicolumn{8}{|l|}{ Grading } \\
\hline G1 & 22 & 10 & 12 & 0.513 & 11 & 11 & 0.152 \\
\hline G2 & 47 & 28 & 19 & & 24 & 23 & \\
\hline G3 & 37 & 19 & 18 & & 26 & 11 & \\
\hline \multicolumn{8}{|l|}{ Pathologic status } \\
\hline Stage I & 17 & 10 & 7 & 0.744 & 9 & 8 & 0.364 \\
\hline Stage II & 61 & 30 & 31 & & 32 & 29 & \\
\hline Stage III & 23 & 14 & 9 & & 16 & 7 & \\
\hline Stage IV & 5 & 3 & 2 & & 4 & 1 & \\
\hline
\end{tabular}

IL-2 $(1,000 \mathrm{U} / \mathrm{ml})$ and the antibodies $(10 \mu \mathrm{g} / \mathrm{ml})$. The apoptosis of $\mathrm{CD} 8^{+} \mathrm{T}$ cells was estimated by Annexin V-FITC/PI (Miltenyi Biotec) following its manufacturer's instructions after co-cultured for $48 \mathrm{~h}$.

Analysis of cytokine secretion. According to the above groups, $\mathrm{CD}^{+} \mathrm{T}$ cells $\left(5 \times 10^{4} /\right.$ well) were co-cultured in 96 -well plates with Ec109 cells (1x10\%/well) at a ratio of 5:1. Cell co-cultures were maintained in complete media with recombinant human IL-2 $(1,000 \mathrm{U} / \mathrm{ml})$ and the antibodies $(10 \mu \mathrm{g} / \mathrm{ml})$. The interferon (IFN)- $\gamma$ was estimated by human IFN- $\gamma$ pre-coating ELISA kit (Dakewe, Beijing, China) following its manufacturer's instructions after co-cultured for $48 \mathrm{~h}$.

Statistical analysis. SPSS 17.0 software was used for statistical analysis. The significance of the difference between PD-Ls expression and several clinical and pathologic variables was assessed by the Chi-square test. The Kaplan-Meier method was used to estimate the probability of survival. Quantitative values were expressed as mean \pm standard deviation or median and range. The t-test and one-way analysis of variance were used to analyze the differences between groups. All statistical tests were conducted as two-sided, and $\mathrm{P}<0.05$ was considered to indicate a statistically significant difference.

\section{Results}

The expression of PD-L1, PD-L2 in ESCC and the correlation with clinicopathological parameters. Expression of PD-L1, PD-L2 and PD-1 was evaluated as staining on the cell membrane and cytoplasm (Fig. 1). The expression of PD-L1 and PD-L2 was detected in tumor cells. The positive expression of PD-L1 and PD-L2 in ESCC tissues was 46.2 and $42.5 \%$, respectively. But no immunoreactivity was found in surrounding normal esophageal tissues. We examined the relationship between PD-L1 and PD-L2 expression and various clinical pathological parameters. However, there was no significant relationship between either PD-L1 or PD-L2 expression with gender, age, tumor location, tumor grade or pathologic stage (Table I).

The correlation between $P D-1^{+}$TILs with the expression of $P D-L 1$ and $P D-L 2$. PD-1 was predominantly expressed in the tumor stromal lymphocytes. The count of PD-1+ TILs in the 106 ESCC cases (the range of the count of PD-1+ TILs in the 106 ESCC cases were 0-16; mean, 6.1) was significantly increased in contrast to that in the normal tissues (0-7; mean, 2.59) $(\mathrm{P}=0.008)$. The mean value of 6.1 was used as the threshold and, accordingly, the 106 tumor cases were divided into PD-1+ $1^{+}$TIL high-density group (60 cases) and low-density group (46 cases). The expression of PD-L1 and PD-L2 was found to inversely correlate with PD- $1^{+}$TILs $(\mathrm{P}<0.05)$ (Table II).

The correlation between PD-L1, PD-L2 expression and prognosis. As shown in Fig. 2, the overall survival of PD-L1 positive patients was significantly worse than that of negative patients $(\mathrm{P}=0.027)$. However, the overall survival of patients positive for PD-L2 tended to be worse than that of negative patients but the difference was not statistically 
Table II. The correlation between PD-1+ TILs with the expression of PD-L1 and PD-L2.

\begin{tabular}{|c|c|c|c|c|c|c|c|}
\hline \multirow[b]{2}{*}{ PD-1+TILs } & \multirow[b]{2}{*}{ Total (n) } & \multicolumn{2}{|c|}{ PD-L1 } & \multirow[b]{2}{*}{ P-value } & \multicolumn{2}{|c|}{ PD-L2 } & \multirow[b]{2}{*}{ P-value } \\
\hline & & Positive & Negative & & Negative & Positive & \\
\hline Low-density & 46 & 18 & 28 & 0.011 & 20 & 26 & 0.017 \\
\hline High-density & 60 & 39 & 21 & & 41 & 19 & \\
\hline Total (n) & 106 & 57 & 49 & & 61 & 45 & \\
\hline
\end{tabular}

A

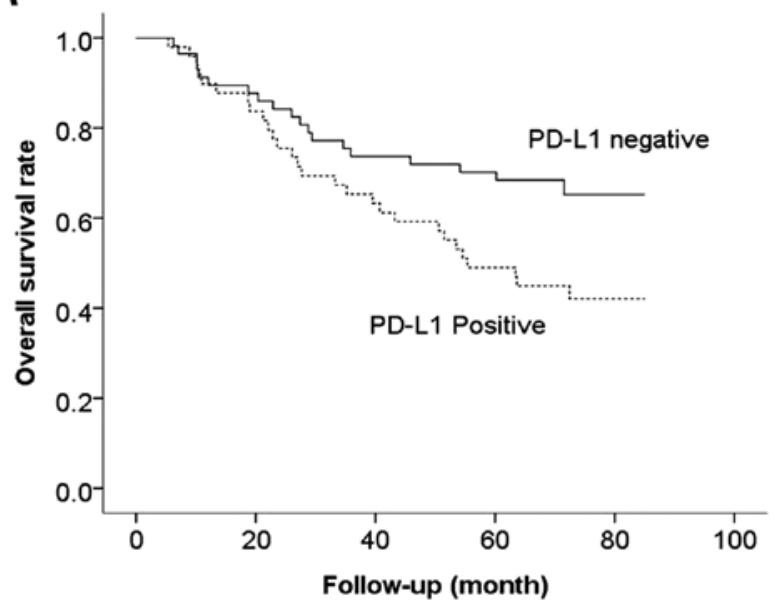

B

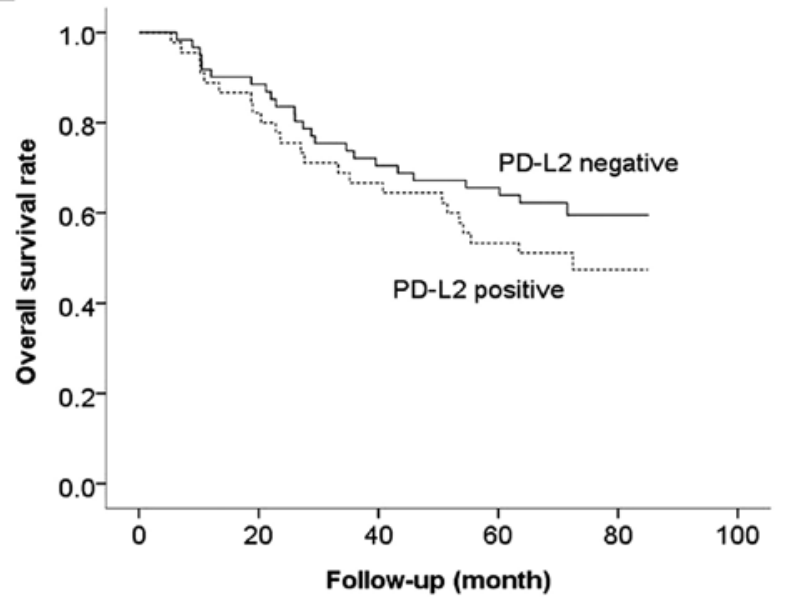

C

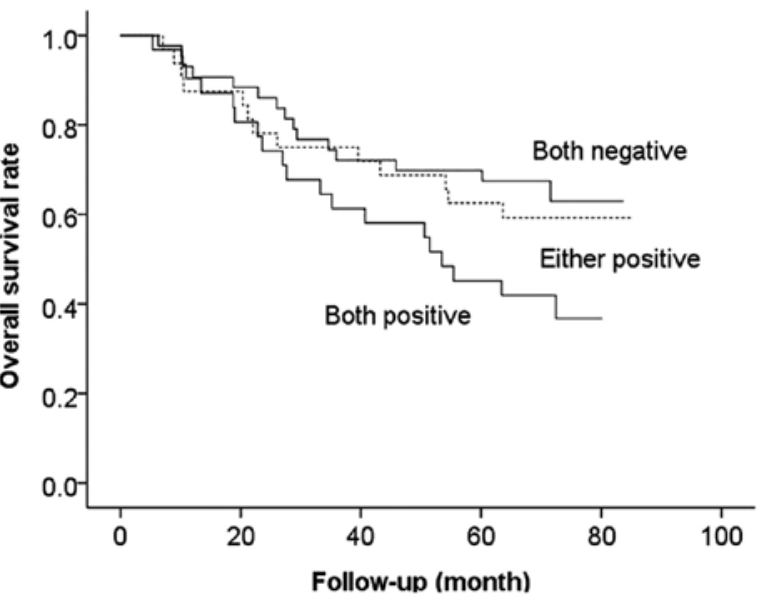

Figure 2. The correlation between PD-L1 and PD-L2 expression and prognosis. (A) PD-L1 positive patients had a poorer prognosis than the negative patients $(\mathrm{P}=0.027)$. (B) The overall survival of patients positive for PD-L2 had a tendency to be worse than that of negative patients but the difference was not statistically significant $(\mathrm{P}=0.243)$. (C) Overall survival of patients with tumors positive for both PD-L1 and PD-L2 was significantly worse than that with tumors negative for both $(\mathrm{P}<0.001)$.

significant $(\mathrm{P}=0.243)$. Furthermore, 31 patients had tumors positive for both PD-L1 and PD-L2, 32 patients had tumors positive for either PD-L1 or PD-L2 and 43 patients had tumors negative for both PD-L1 and PD-L2. Overall survival of patients with tumors positive for both PD-L1 and PD-L2 was significantly worse than that with tumors negative for both $(\mathrm{P}<0.001)$. In addition, overall survival of patients positive for either PD-L1 or PD-L2 had a tendency to be better than that with both positive and worse than that with both negative, although the differences were not statistically significant $(\mathrm{P}=0.094)$.
The expression of PD-L1, PD-L2 and PD-1 on Ec109 and $C D 8^{+} T$ cells. As shown in Fig. 3, the expression of PD-L1 on Ec109 cell line was not high $(24.5 \pm 4.2 \%)$, and Ec109 cell line did not express PD-L2 and PD-1. We subsequently examined the expression of PD-L1 and PD-L2 on Ec109 cells before and after transfection. Ec109/PD-L1 cells and Ec109/PD-L2 cells were selected with high levels of PD-L1 (97.3) and PD-L2 (93.6\%) for further study. Transcriptions of PD-L1 gene and PD-L2 gene were identified by qRT-PCR indicated that the stable transfected Ec109 cell line was successfully established (Fig. 4). The purity of $\mathrm{CD}^{+} \mathrm{T}$ cells before and 
A

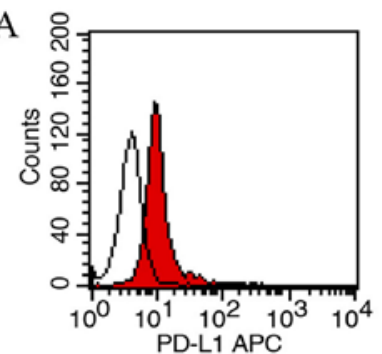

$\mathrm{D}$
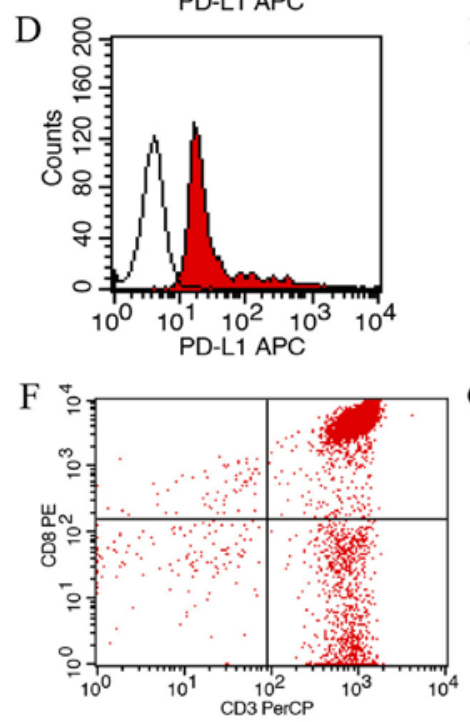

B

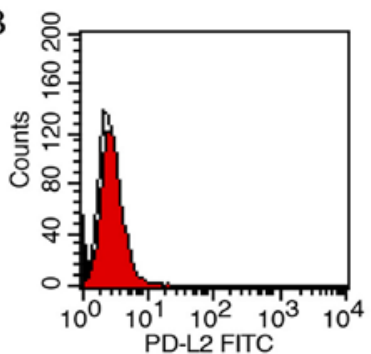

E
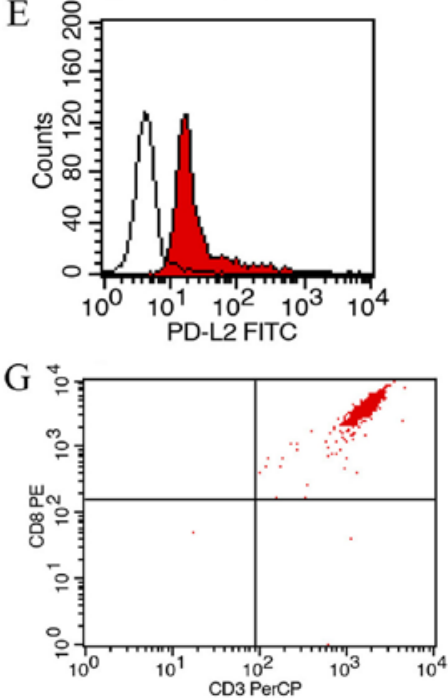

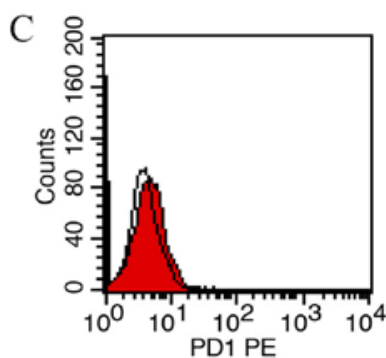

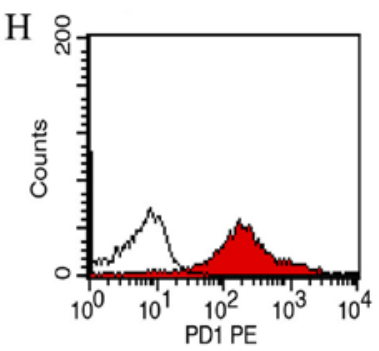

Figure 3. The expression rate of PD-L1 on Ec109 cell line was 24.5 $\pm 4.2 \%$ (A). Ec109 cell line did not express PD-L2 and PD-1 (B and C). After transfection, Ec109/PD-L1 cells and Ec109/PD-L2 cells were selected with high levels of PD-L1 (97.3\%, D) and PD-L2 (93.6\%, E). The purity of CD8 ${ }^{+} \mathrm{T}$ cells before and after separation by MACS was $75.2 \%$ (F) and $99.7 \%$, respectively (G). In addition, the expression of PD-1 on CD8 ${ }^{+}$T cells separated by MACS was $91.2 \%$ (H).

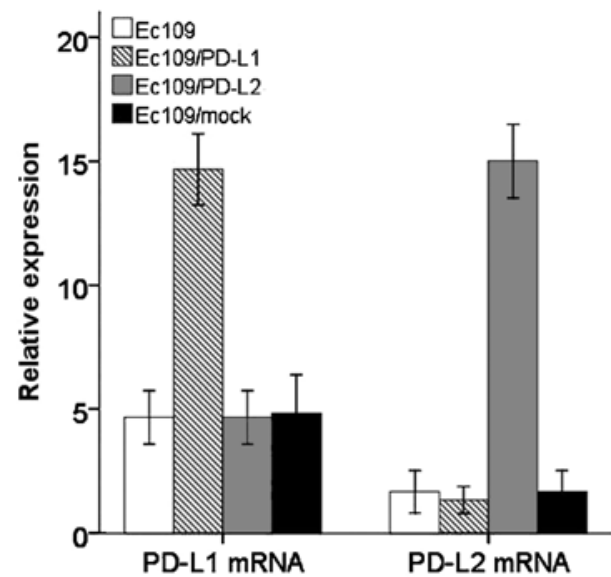

Figure 4. The levels of PD-L1 and PD-L2 mRNA in Ec109 cells before and after transfection were detected by qRT-PCR. The expression of both PD-L1 in Ec109/PD-L1 cells and PD-L2 in Ec109/PD-L2 cells were significantly elevated compared with normal Ec109 cells and Ec109/mock cells $(\mathrm{P}<0.001)$

after separation by MACS was 75.2 and $99.7 \%$, respectively. In addition, the expression of PD-1 in $\mathrm{CD} 8^{+} \mathrm{T}$ cells separated by MACS was $91.2 \%$ (Fig. 3).

Functional significance of $P D-L 1$ and $P D-L 2$ for purified allogeneic $C D 8^{+} T$ cells. After co-cultured, the Ec109/PD-L1 cells caused a decrease in $\mathrm{CD}^{+} \mathrm{T}$ cell proliferation, IFN- $\gamma$ production and increased apoptosis compared with the control group. However, blockade of PD-L1 or PD-1 with antibodies

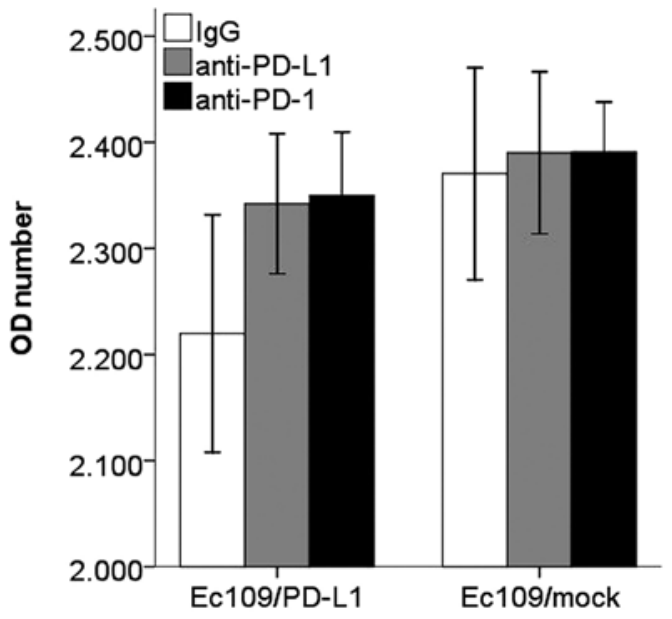

Figure 5. The effect of PD-L1 on the proliferation of $\mathrm{CD} 8^{+} \mathrm{T}$ cells. The Ec109/PD-L1 IgG group caused decreased proliferation of CD8 ${ }^{+} \mathrm{T}$ cells, compared with the control Ec109/mock IgG group ( $\mathrm{P}=0.001)$. However, blockade of PD-L1 or PD-1 with antibodies resulted in enhanced proliferation of $\mathrm{CD} 8^{+} \mathrm{T}$ cells $(\mathrm{P}=0.006$ and $\mathrm{P}=0.004$, respectively).

resulted in enhanced $\mathrm{CD}^{+} \mathrm{T}$ cells proliferation, IFN- $\gamma$ production and decreased apoptosis (Figs. 5-8).

There was significant inhibitory effect of PD-L2 on the $\mathrm{CD}^{+} \mathrm{T}$ cell IFN- $\gamma$ secretion, and this inhibitory effect could be restored with PD-L2 or PD-1 blocking antibody (Fig. 9). However, $\mathrm{CD}^{+} \mathrm{T}$ cells proliferation and apoptosis in PD-L2 signal test were not altered significantly (Figs. 10 and 11). 


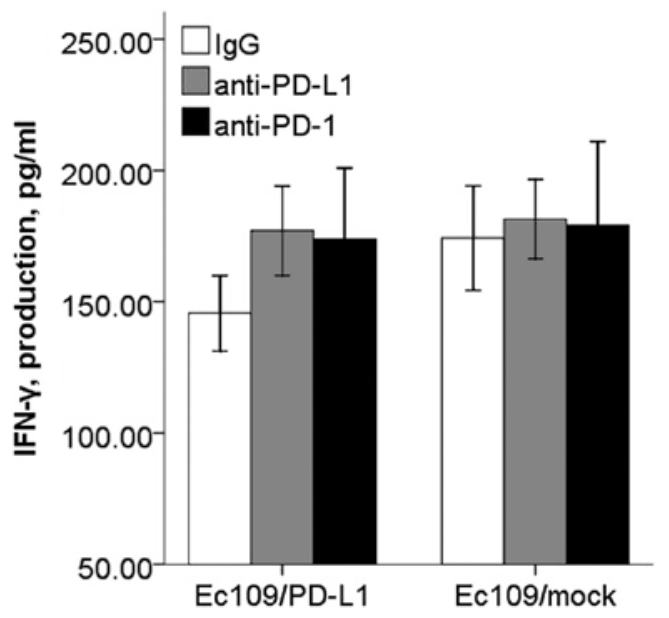

Figure 6. The effect of PD-L2 on the proliferation of $\mathrm{CD} 8^{+} \mathrm{T}$ cells. There was no significant difference between each group (Ec109/PD-L2 + IgG group vs. Ec109/mock + IgG group, P=0.951; Ec109/PD-L2 + IgG group vs. Ec109/PD-L2 + PD-L2 antibody group, P=0.916; Ec109/PD-L2 + IgG group vs. Ec109/PD-L2 + PD-1 antibody group, $\mathrm{P}=0.892$ ).

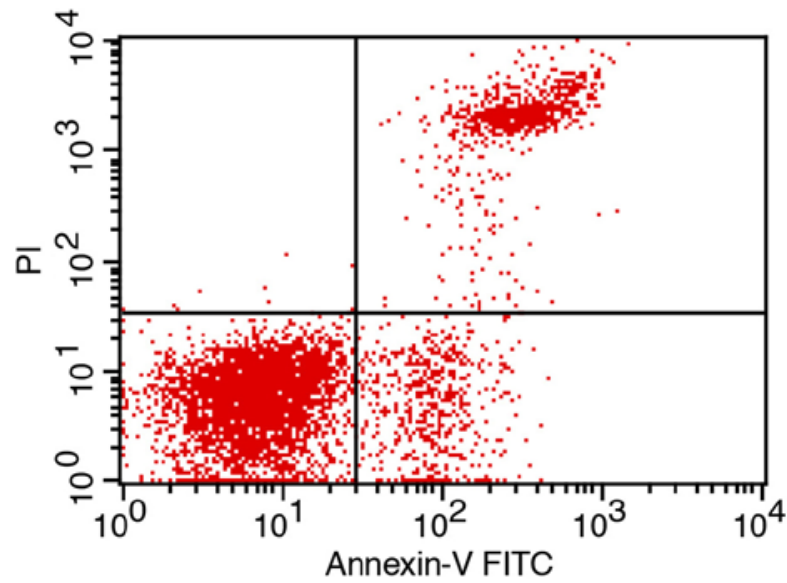

Figure 7. Flow cytometry of $\mathrm{CD} 8^{+} \mathrm{T}$ cell apoptosis. According to the size and different structures of cells, $\mathrm{CD}^{+} \mathrm{T}$ cells and Ec109 cells can be divided into two groups by FCM. The apoptosis percentage of $\mathrm{CD} 8^{+} \mathrm{T}$ cells was estimated by Annexin V-FITC.

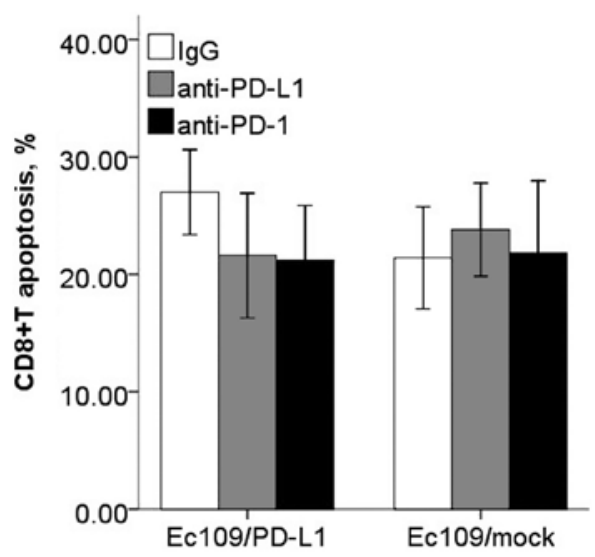

Figure 8. The effect of PD-L1 on the apoptosis of $\mathrm{CD} 8^{+} \mathrm{T}$ cells. The Ec109/PD-L1 IgG group caused increased apoptosis of CD8 ${ }^{+} \mathrm{T}$ cells, compared with the control Ec109/mock IgG group $(\mathrm{P}=0.030)$. However, blockade of PD-L1 or PD-1 with antibodies resulted in reduced apoptosis of $\mathrm{CD} 8^{+} \mathrm{T}$ cells $(\mathrm{P}=0.036$ and $\mathrm{P}=0.025$, respectively).

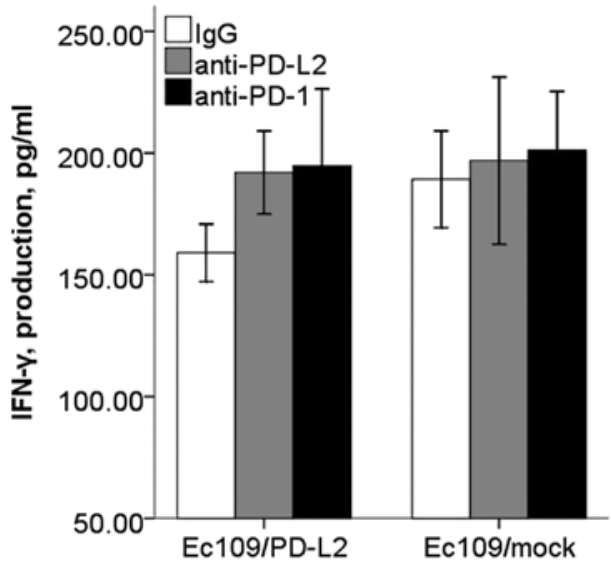

Figure 9. The effect of PD-L2 on apoptosis of $\mathrm{CD}^{+} \mathrm{T}$ cells. There was no significant difference between each group (Ec109/PD-L2 + IgG group vs. Ec109/mock + IgG group, $\mathrm{P}=0.605 ; \mathrm{Ec109} / \mathrm{PD}-\mathrm{L} 2+\mathrm{IgG}$ group vs. Ec109/PD-L2 + PD-L2 antibody group, P=0.756; Ec109/PD-L2 + IgG group vs. Ec109/PD-L2 + PD-1 antibody group, $\mathrm{P}=0.354)$.

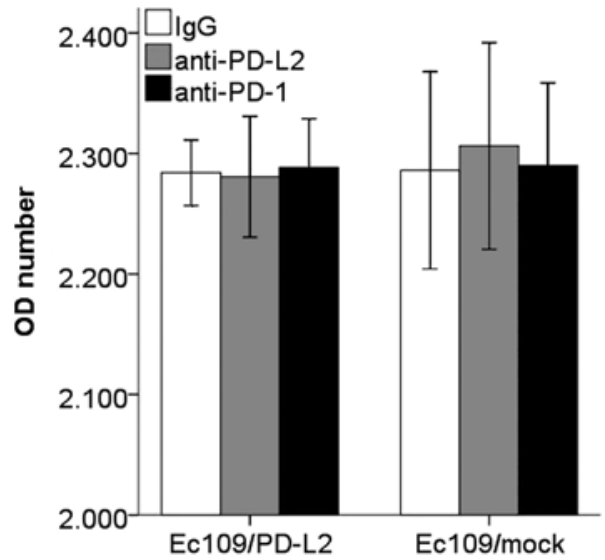

Figure 10. The effect of PD-L1 on the IFN- $\gamma$ secretion of $\mathrm{CD}^{+} \mathrm{T}$ cells. The Ec109/PD-L1 IgG group caused decreased IFN- $\gamma$ secretion of CD8 ${ }^{+} \mathrm{T}$ cells, compared with the control Ec109/mock IgG group $(\mathrm{P}=0.017)$. However, blockade of PD-L1 or PD-1 with antibodies resulted in enhanced IFN- $\gamma$ secretion of $\mathrm{CD}^{+} \mathrm{T}$ cells $(\mathrm{P}=0.010$ and $\mathrm{P}=0.018$, respectively).

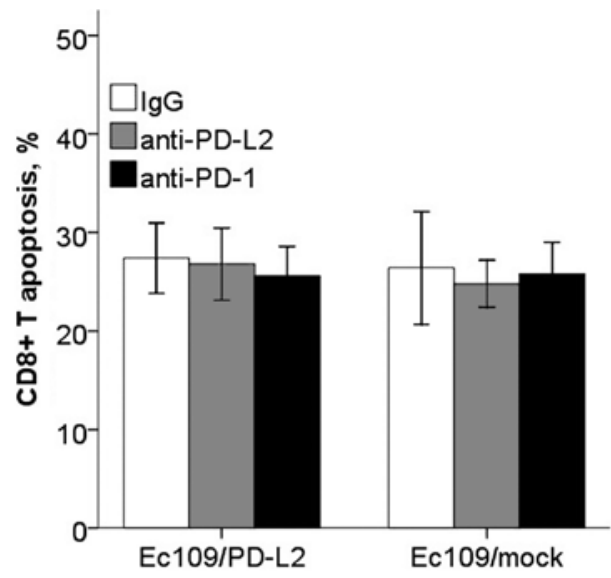

Figure 11. The effect of PD-L2 on the IFN- $\gamma$ secretion of $\mathrm{CD} 8^{+} \mathrm{T}$ cells. The Ec109/PD-L2 IgG group caused decreased IFN- $\gamma$ secretion of $\mathrm{CD}^{+} \mathrm{T}$ cells, compared with the control Ec109/mock IgG group ( $\mathrm{P}=0.023)$. However, blockade of PD-L2 or PD-1 with antibodies resulted in enhanced IFN- $\gamma$ secretion of $\mathrm{CD}^{+} \mathrm{T}$ cells $(\mathrm{P}=0.014$ and $\mathrm{P}=0.008$, respectively). 


\section{Discussion}

Despite the presence of large numbers of TILs in cancer tissues, the immune system often fails to prevent tumor development and progression (24-27). Recent studies have suggested a novel mechanism that tumor may evade host immune response through the expression of PD-L1 and PD-L2. PD-L1 and PD-L2 have been thought to be involved in the negative regulation of cellular and humoral immune responses by engaging PD-1 receptor on activated $\mathrm{T}$ and B cells $(28,29)$.

However, there is no previous study on the expression of PD-L1, PD-L2 and PD-1 simultaneously in ESCC tissues. Our results show PD-L1, PD-L2 and PD-1 were aberrantly over expressed in ESCC tissues. PD-L1 and PD-L2 proteins both located on cytoplasm and cell membrane of tumor cells. We found that $46.2 \%$ of ESCC tissues evaluated in this study were positive for PD-L1 and 42.5\% ESCC tissues were positive for PD-L2. Furthermore, PD-L1-positive patients had significantly poorer prognosis than the negative patients. Though PD-L2 expression was correlated with an impaired survival, this difference was not statistically significant. However, there was no significant relationship between either PD-L1 or PD-L2 expression with the age, gender, lesion location, differentiated degree and pathologic stage.

PD-L1 expression has been detected in most human cancers, such as gastric, pancreatic, kidney, breast, ovarian and bladder urothelial cancers. In renal cell carcinoma, tumor PD-L1 expression has been shown to correlate with rapid cancer progression, cancer death and overall mortality $(22,30)$. In urothelial cell carcinoma, tumor-associated PD-L1 expression was found to be significantly associated with a high frequency of postoperative recurrence, poorer survival rate, and advanced tumor stage (31). In pancreatic cancer, patients with cancer-cell associated PD-L1-positive expression had a significantly poorer prognosis than patients with PD-L1negative tumors $(32,33)$. In gastric carcinoma, patients with PD-L1-positive tumors also had a significantly decreased probability of survival compared with patients with PD-L1negative tumors (34).

The research on PD-L2 in malignant tumors is still relatively rare. In a study of pancreatic cancer, no correlation was found between PD-L2 expression and survival (32). In ovarian cancer, although PD-L2 expression was correlated with an impaired survival, this did not reach statistical significance (35). Similarly, in hepatocellular carcinoma a minority had high PD-L2 expression, and again, although PD-L2 expression was correlated with an impaired disease-free survival, this difference was not statistically significant (36). Only one report suggested that the expression of PD-L2 was significantly correlated with poorer prognosis in ESCC (23). Thus, the majority of studies have found a significant correlation between impaired survival and PD-L1 expression, but much less so for PD-L2. Currently, the expression of PD-L2 research conclusion remains controversial in tumor tissues.

TILs are considered as a manifestation of the host immune response (37). Several clinical studies have suggested that TILs play a critical role and have prognostic significance in certain human tumors including esophageal cancer (38-40). PD-1 mainly expressed on TILs. In our research, we showed for the first time that the count of PD- $1^{+}$TILs was negatively correlated with both PD-L1 and PD-L2 expression in ESCC. The results of the current study indicated that the expression of PD-L1 and PD-L2 on ESCC inhibits PD-1+ TILs activity or promote $\mathrm{PD}-1^{+}$TILs apoptosis, ultimately promoting immune evasion via the PD-1/PD-Ls pathway.

In order to further study the effects of PD-L1 and PD-L2 on immune cells, we measured the PD-L1, PD-L2 and PD-1 expression of Ec109 cells by FCM. The percentage of PD-L1 positive cells on Ec109 was $24.5 \pm 4.2 \%$. The Ec109 cells did not express PD-L2 and PD-1. Then stable transfected Ec109 cell line was established and PD-L1/PD-L2 gene was expressed successfully. Transcription of PD-L1 gene and PD-L2 gene were identified by qRT-PCR. This has not been reported in ESCC, and can be used as a model applied to further studies on PD-L1 and PD-L2.

Furthermore, we have analyzed the PD-1/PD-Ls signal pathway on the function of $\mathrm{CD} 8^{+} \mathrm{T}$ cells for the first time by co-culturing Ec109 and $\mathrm{CD}^{+} \mathrm{T}$ cells. We chose the $\mathrm{CD}^{+} \mathrm{T}$ lymphocytes in the function experiment, because $\mathrm{CD} 8^{+} \mathrm{T}$ cells are generally thought to play a central role in antitumor immune response and the presence of $\mathrm{CD} 8^{+} \mathrm{T}$ was reported as a prognostic factor in esophageal cancer $(38,39)$. $\mathrm{CD}^{+} \mathrm{T}$ cells can also produce IFN- $\gamma$, which is an important activator of macrophages and inducer of class II major histocompatibility complex (MHC) molecule expression, and IFN- $\gamma$ has antiviral, immunoregulatory and antitumor properties (41).

The Ec109 cells and purified activated $\mathrm{CD} 8^{+} \mathrm{T}$ cells were co-cultured for $48 \mathrm{~h}$. PD-L1 significantly inhibited the CD8 ${ }^{+}$ $\mathrm{T}$ cells proliferation, IFN- $\gamma$ secretion and enhanced the apoptosis, which could be restored with the presence of PD-L1 and PD-1 blocking antibody. PD-L2 significantly inhibited the IFN- $\gamma$ secretion of $\mathrm{CD}^{+} \mathrm{T}$ cells, and this could be restored with the presence of PD-L2 and PD-1 blocking antibody. But no significant result was obtained in the proliferation and apoptosis experiments. PD-1/PD-Ls interactions lead to phosphorylation of two tyrosines at the intracellular tail of PD-1. These tyrosines are part of an immunoreceptor tyrosine-based inhibitory motif (ITIM) and an immunoreceptor tyrosine-based switch motif (ITSM). ITSM then recruits either of two structurally-related protein tyrosine phosphatases (42), which suppress activation of PI3K/Akt (43). Consequently, the survival factor Bcl-xL is downregulated and expression of transcription factors associated with effector cell function including GATA-3, T-bet and Eomes are lost (44). The net result of these PD-1-induced cascades is an impairment of proliferation, cytokine production, cytolytic function, and survival of the $\mathrm{CD} 8^{+} \mathrm{T}$ cells (45).

However, the results of PD-L1 and PD-L2 are not identical. These data indicate that PD-L1 and PD-L2 may have different roles in tolerance induction, as Rozali et al (46) concluded that PD-L2 could play a role in the modulation of T-cell function, but the exact molecular pathway was yet to be elucidated. Of note, PD-1 may not be the only receptor for PD-L2. This can be inferred from helminth infection and allergic animal models, showing enhanced disease severity when PD-L2 blocking antibodies were used, but not when PD-1 blocking antibodies were used $(47,48)$. Furthermore, PD-L2 mutants with abolished PD-1 binding capacity could 
still exert functional effects on $\mathrm{T}$ cells from normal and PD-1-deficient mice (49). Thus, the role of PD-L2 still is not clear.

Activation of the immune system is recognized as an important treatment strategy against cancer (50). In fact, therapeutic antibodies for blocking PD-1 and PD-L1 have been developed and are undergoing human clinical testing $(51,52)$. Although PD-1 and PD-L1 directed therapy is currently undergoing investigation in several types of malignancies, including both solid tumors and hematologic malignancies, PD-1 and PD-L1 therapy has been most studied in patients with metastatic melanoma. Antibodies targeting PD-1 in clinical development include nivolumab, pembrolizumab and pidilizumab. The first antibody to target PD-L1 in clinical trials was MDX-1105. Antibodies currently in clinical development that target PD-L1 include MPDL3280A, MEDI4736 and MSB0010718C. These clinical trials result in durable responses and relative safety in patients with a wide range of cancers $(20,21)$. These therapeutic antibodies for blocking PD-1 and PD-L1 have broad application prospects.

However, immunotherapy in ESCC is still immature. Our finding revealed that PD-L1, PD-L2 and PD-1 were aberrantly expressed in ESCC and they might thwart effective antitumor immunity by interaction with tumor-T-cell, which provides an important clue to reveal the cellular immune deficiency mechanism in ESCC. Thus, more research in animal models, and in human are necessary to fully delineate the immune regulation functions of $\mathrm{PD}-\mathrm{Ls}$ as well as molecule mediation mechanism involved in ESCC. How to selectively block these inhibitory molecules will be an attractive approach for ESCC immunotherapy.

\section{Acknowledgements}

The present study was supported by the assistance of the Central Laboratory in the Affiliated Cancer Hospital of Zhengzhou University, the Biological Treatment Center and Institute of Digestive of the Second Affiliated Hospital of Zhengzhou University.

\section{References}

1. Jemal A, Bray F, Center MM, Ferlay J, Ward E and Forman D: Global cancer statistics. CA Cancer J Clin 61: 69-90, 2011.

2. Cohen DJ and Ajani J: An expert opinion on esophageal cancer therapy. Expert Opin Pharmacother 12: 225-239, 2011.

3. Lagergren J and Lagergren P: Oesophageal cancer. BMJ 341: c6280, 2010.

4. Cunningham D, Allum WH, Stenning SP, Thompson JN, Van de Velde CJ, Nicolson M, Scarffe JH, Lofts FJ, Falk SJ, Iveson TJ, et al; MAGIC Trial Participants: Perioperative chemotherapy versus surgery alone for resectable gastroesophageal cancer. N Engl J Med 355: 11-20, 2006.

5. Siewert JR, Lordick F, Ott K, Stein HJ, Weber WA, Becker K, Peschel C, Fink U and Schwaiger M: Induction chemotherapy in Barrett cancer: Influence on surgical risk and outcome. Ann Surg 246: 624-628, discussion 628-631, 2007.

6. Gebski V, Burmeister B, Smithers BM, Foo K, Zalcberg J and Simes J; Australasian Gastro-Intestinal Trials Group: Survival benefits from neoadjuvant chemoradiotherapy or chemotherapy in oesophageal carcinoma: A meta-analysis. Lancet Oncol 8 : 226-234, 2007

7. Dong H, Strome SE, Salomao DR, Tamura H, Hirano F, Flies DB, Roche PC, Lu J, Zhu G, Tamada K, et al: Tumor-associated B7-H1 promotes T-cell apoptosis: A potential mechanism of immune evasion. Nat Med 8: 793-800, 2002.
8. Dong $\mathrm{H}$ and Chen L: B7-H1 pathway and its role in the evasion of tumor immunity. J Mol Med (Berl) 81: 281-287, 2003.

9. Flies DB and Chen L: The new B7s: Playing a pivotal role in tumor immunity. J Immunother 30: 251-260, 2007.

10. Sharpe AH and Freeman GJ: The B7-CD28 superfamily. Nat Rev Immunol 2: 116-126, 2002.

11. Ishida Y, Agata Y, Shibahara K and Honjo T: Induced expression of PD-1, a novel member of the immunoglobulin gene superfamily, upon programmed cell death. EMBO J 11: 3887-3895, 1992.

12. Nishimura $\mathrm{H}$ and Honjo T: PD-1: An inhibitory immunoreceptor involved in peripheral tolerance. Trends Immunol 22: 265-268, 2001.

13. Dong H, Zhu G, Tamada K and Chen L: B7-H1, a third member of the B7 family, co-stimulates T-cell proliferation and interleukin-10 secretion. Nat Med 5: 1365-1369, 1999.

14. Freeman GJ, Long AJ, Iwai Y, Bourque K, Chernova T, Nishimura H, Fitz LJ,Malenkovich N, Okazaki T, Byrne MC, et al: Engagement of the PD-1 immunoinhibitory receptor by a novel B7 family member leads to negative regulation of lymphocyte activation. J Exp Med 192: 1027-1034, 2000.

15. Tseng SY, Otsuji M, Gorski K, Huang X, Slansky JE, Pai SI, Shalabi A, Shin T, Pardoll DM and Tsuchiya H: B7-DC, a new dendritic cell molecule with potent costimulatory properties for T cells. J Exp Med 193: 839-846, 2001.

16. Latchman Y, Wood CR, Chernova T, Chaudhary D, Borde M, Chernova I, Iwai Y, Long AJ, Brown JA, Nunes R, et al: PD-L2 is a second ligand for PD-1 and inhibits $\mathrm{T}$ cell activation. Nat Immunol 2: 261-268, 2001.

17. Mahoney KM, Freeman GJ and McDermott DF: The next immune-checkpoint inhibitors: PD-1/PD-L1 blockade in melanoma. Clin Ther 37: 764-782, 2015.

18. Massari F, Santoni M, Ciccarese C, Santini D, Alfieri S, Martignoni G, Brunelli M, Piva F, Berardi R, Montironi R, et al: PD-1 blockade therapy in renal cell carcinoma: Current studies and future promises. Cancer Treat Rev 41: 114-121, 2015.

19. Suzuki H, Owada Y, Watanabe Y, Inoue T, Fukuharav M, Yamaura T, Mutoh S, Okabe N, Yaginuma H, Hasegawa T, et al: Recent advances in immunotherapy for non-small-cell lung cancer. Hum Vaccin Immunother 10: 352-357, 2014.

20. Topalian SL, Hodi FS, Brahmer JR, Gettinger SN, Smith DC, McDermott DF, Powderly JD, Carvajal RD, Sosman JA, Atkins MB, et al: Safety, activity, and immune correlates of anti-PD-1 antibody in cancer. N Engl J Med 366: 2443-2454, 2012.

21. Brahmer JR, Tykodi SS, Chow LQ, Hwu WJ, Topalian SL, Hwu P, Drake CG, Camacho LH, Kauh J, Odunsi K, et al: Safety and activity of anti-PD-L1 antibody in patients with advanced cancer. N Engl J Med 366: 2455-2465, 2012.

22. Thompson RH, Kuntz SM, Leibovich BC, Dong H, Lohse CM, Webster WS, Sengupta S, Frank I, Parker AS, Zincke H, et al: Tumor B7-H1 is associated with poor prognosis in renal cell carcinoma patients with long-term follow-up. Cancer Res 66: 3381-3385, 2006

23. Ohigashi Y, Sho M, Yamada Y, Tsurui Y, Hamada K, Ikeda N, Mizuno T, Yoriki R, Kashizuka H, Yane K, et al: Clinical significance of programmed death-1 ligand-1 and programmed death-1 ligand-2 expression in human esophageal cancer. Clin Cancer Res 11: 2947-2953, 2005.

24. Cordon-Cardo C, Fuks Z, Drobnjak M, Moreno C, Eisenbach L and Feldman M: Expression of HLA-A,B,C antigens on primary and metastatic tumor cell populations of human carcinomas. Cancer Res 51: 6372-6380, 1991.

25. Restifo NP, Esquivel F, Kawakami Y, Yewdell JW, Mulé JJ, Rosenberg SA and Bennink JR: Identification of human cancers deficient in antigen processing. J Exp Med 177: 265-272, 1993.

26. Ebrahimi B, Tucker SL, Li D, Abbruzzese JL and Kurzrock R: Cytokines in pancreatic carcinoma: Correlation with phenotypic characteristics and prognosis. Cancer 101: 2727-2736, 2004.

27. Pardoll D: Does the immune system see tumors as foreign or self? Annu Rev Immunol 21: 807-839, 2003.

28. Liu X, Gao JX, Wen J, Yin L, Li O, Zuo T, Gajewski TF, Fu YX, Zheng P and Liu Y: B7DC/PDL2 promotes tumor immunity by a PD-1-independent mechanism. J Exp Med 197: 1721-1730, 2003.

29. Okazaki T, Maeda A, Nishimura H, Kurosaki T and Honjo T: PD-1 immunoreceptor inhibits B cell receptor-mediated signaling by recruiting src homology 2 -domain-containing tyrosine phosphatase 2 to phosphotyrosine. Proc Natl Acad Sci USA 98: 13866-13871, 2001. 
30. Thompson RH, Gillett MD, Cheville JC, Lohse CM, Dong H, Webster WS, Krejci KG, Lobo JR, Sengupta S, Chen L, et al: Costimulatory B7-H1 in renal cell carcinoma patients: Indicator of tumor aggressiveness and potential therapeutic target. Proc Natl Acad Sci USA 101: 17174-17179, 2004.

31. Nakanishi J, Wada Y, Matsumoto K, Azuma M, Kikuchi K and Ueda S: Overexpression of B7-H1 (PD-L1) significantly associates with tumor grade and postoperative prognosis in human urothelial cancers. Cancer Immunol Immunother 56: 1173-1182, 2007.

32. Nomi T, Sho M, Akahori T, Hamada K, Kubo A, Kanehiro H, Nakamura S, Enomoto K, Yagita H, Azuma M, et al: Clinical significance and therapeutic potential of the programmed death-1 ligand/programmed death-1 pathway in human pancreatic cancer. Clin Cancer Res 13: 2151-2157, 2007.

33. Loos M, Giese NA, Kleeff J, Giese T, Gaida MM, Bergmann F, Laschinger M, W Büchler M and Friess $\mathrm{H}$ : Clinical significance and regulation of the costimulatory molecule $\mathrm{B} 7-\mathrm{H} 1$ in pancreatic cancer. Cancer Lett 268: 98-109, 2008.

34. Wu C, Zhu Y, Jiang J, Zhao J, Zhang XG and Xu N: Immunohistochemical localization of programmed death-1 ligand-1 (PD-L1) in gastric carcinoma and its clinical significance. Acta Histochem 108: 19-24, 2006.

35. Hamanishi J, Mandai M, Iwasaki M, Okazaki T, Tanaka Y, Yamaguchi K, Higuchi T, Yagi H, Takakura K, Minato N, et al: Programmed cell death 1 ligand 1 and tumor-infiltrating $\mathrm{CD}^{+}$ $\mathrm{T}$ lymphocytes are prognostic factors of human ovarian cancer. Proc Natl Acad Sci USA 104: 3360-3365, 2007.

36. Gao Q, Wang XY, Qiu SJ, Yamato I, Sho M, Nakajima Y, Zhou J, Li BZ, Shi YH, Xiao YS, et al: Overexpression of PD-L1 significantly associates with tumor aggressiveness and postoperative recurrence in human hepatocellular carcinoma. Clin Cancer Res 15: 971-979, 2009.

37. Rosenberg SA: The immunotherapy of solid cancers based on cloning the genes encoding tumor-rejection antigens. Annu Rev Med 47: 481-491, 1996.

38. Cho Y, Miyamoto M, Kato K, Fukunaga A, Shichinohe T, Kawarada Y, Hida Y, Oshikiri T, Kurokawa T, Suzuoki M, et al: $\mathrm{CD} 4^{+}$and $\mathrm{CD} 8^{+} \mathrm{T}$ cells cooperate to improve prognosis of patients with esophageal squamous cell carcinoma. Cancer Res 63: 1555-1559, 2003.

39. Schumacher K, Haensch W, Röefzaad C and Schlag PM: Prognostic significance of activated CD8(+) T cell infiltrations within esophageal carcinomas. Cancer Res 61: 3932-3936, 2001.

40. Ropponen KM, Eskelinen MJ, Lipponen PK, Alhava E and Kosma VM: Prognostic value of tumour-infiltrating lymphocytes (TILs) in colorectal cancer. J Pathol 182: 318-324, 1997.
41. Schroder K, Hertzog PJ, Ravasi $T$ and Hume DA: Interferon-gamma: An overview of signals, mechanisms and functions. J Leukoc Biol 75: 163-189, 2004.

42. Chemnitz JM, Parry RV, Nichols KE, June CH and Riley JL: SHP-1 and SHP-2 associate with immunoreceptor tyrosine-based switch motif of programmed death 1 upon primary human $\mathrm{T}$ cell stimulation, but only receptor ligation prevents $\mathrm{T}$ cell activation. J Immunol 173: 945-954, 2004.

43. Parry RV, Chemnitz JM, Frauwirth KA, Lanfranco AR, Braunstein I, Kobayashi SV, Linsley PS, Thompson CB and Riley JL: CTLA-4 and PD-1 receptors inhibit T-cell activation by distinct mechanisms. Mol Cell Biol 25: 9543-9553, 2005.

44. Nurieva R, Thomas S, Nguyen T, Martin-Orozco N, Wang Y, Kaja MK, Yu XZ and Dong C: T-cell tolerance or function is determined by combinatorial costimulatory signals. EMBO J 25: 2623-2633, 2006

45. Riley JL: PD-1 signaling in primary T cells. Immunol Rev 229: 114-125, 2009

46. Rozali EN, Hato SV, Robinson BW, Lake RA and Lesterhuis J: Programmed death ligand 2 in cancer-induced immune suppression. Clin Dev Immunol 2012: 656340, 2012.

47. Matsumoto $K$, Inoue $H$, Nakano $T$, Tsuda M, Yoshiura $Y$, Fukuyama S, Tsushima F, Hoshino T, Aizawa H, Akiba H, et al: B7-DC regulates asthmatic response by anIFN-gamma-dependent mechanism. J Immunol 172: 2530-2541, 2004.

48. Ishiwata K, Watanabe N, Guo M, Tomihara K, Brumlik MJ, Yagita H, Pardoll D, Chen L and Shin T: Costimulator B7-DC attenuates strong Th2 responses induced by Nippostrongylus brasiliensis. J Immunol 184: 2086-2094, 2010.

49. Wang S, Bajorath J, Flies DB, Dong H, Honjo T and Chen L: Molecular modeling and functional mapping of B7-H1 and B7-DC uncouple costimulatory function from PD-1 interaction. J Exp Med 197: 1083-1091, 2003.

50. Hanahan D and Weinberg RA: Hallmarks of cancer: The next generation. Cell 144: 646-674, 2011

51. Yang W, Chen PW, Li H, Alizadeh H and Niederkorn JY: PD-L1: PD-1 interaction contributes to the functional suppression of T-cell responses to human uveal melanoma cells in vitro. Invest Ophthalmol Vis Sci 49: 2518-2525, 2008.

52. Topalian SL, Drake CG and Pardoll DM: Targeting the PD-1/B7-H1(PD-L1) pathway to activate anti-tumor immunity. Curr Opin Immunol 24: 207-212, 2012. 